\title{
PRODUÇÃO DE MUDAS DE ALFACE COM O USO DE SUBSTRATO PREPARADO COM COPRÓLITOS DE MINHOCA
}

\section{Prodution of seedlings of lettuce with the use of prepared substrate with earthworm casting}

\author{
Suzana Rodrigues de Souza ${ }^{1}$, Yrle da Rocha Fontinele ${ }^{2}$, Cristina Szilagyi Saldanha ${ }^{3}$, \\ Sebastião Elviro de Araújo Neto ${ }^{4}$, Jorge Ferreira Kusdra ${ }^{5}$
}

\begin{abstract}
RESUMO
Com o objetivo de avaliar o efeito de coprólitos de minhoca (Chibui bari Righi \& Guerra, 1985) na produção de mudas de alface (Lactuca sativa L.) cv. Simpson, realizaram-se dois experimentos em casa de vegetação na Universidade Federal do Acre, ambos no delineamento experimental inteiramente casualizado, com seis tratamentos e seis repetições, totalizando 36 unidades experimentais, representadas por copos plásticos de $180 \mathrm{~cm}^{3}$. Os tratamentos foram definidos a partir da mistura de seis concentrações $(0,20,40$, 60,80 e 100\%) de solo e coprólitos. Utilizaram-se dois tipos de solo, eutrófico no experimento 1 e distrófico no experimento 2 . Aos 34 dias após a semeadura avaliaram-se a matéria seca da parte aérea, da raiz e total da planta. Os resultados do experimento 1 indicam que o acréscimo de coprólitos a solos eutróficos promove máximo incremento de massa seca da parte aérea e total da planta com concentrações de coprólitos de 13,49\% e 17,88\%, respectivamente. Entretanto, os resultados do experimento 2 indicam que a adição de coprólitos a solos distróficos, responde a uma função cúbica, com máximo incremento de massa seca da raiz e total da planta com concentrações de coprólitos de $17,49 \%$ e $21,40 \%$, respectivamente, com decréscimo em $68,23 \%$ e $67,48 \%$, e incremento máximo novamente com $100 \%$ de coprólitos para ambas características. O uso de substratos preparados com solo e coprólitos de minhoca somente contribui para o crescimento de mudas de alface se a condição química dos coprólitos for mais adequada que a do solo em atender as necessidades nutricionais das plantas.
\end{abstract}

Termos para indexação: Lactuca sativa, Adubação orgânica, Chibui bari.

\begin{abstract}
With the aim of evaluating the effect of earthworm casting (Chibui bari Righi \& Guerra, 1985) in the production of lettuce seedlings (Lactuca sativa L.) cv. Simpson, two experiments ware carried out in greenhouse in the Federal University of the Acre, both in a completely randomized outline with six treatments and six repetitions, totalizing 36 experimental units, represented by $180 \mathrm{~cm}^{3}$ plastic cups. The treatments were defined from the mixture of six concentrations $(0,20,40,60,80$ and $100 \%)$ of soil and earthworm casting. Two soil types were used, eutrophic in the experiment 1, and dystrophic in experiment 2 . At 34 days after the sowing the dry mass of shoot, root and total plant were evaluated. The results of experiment 1 indicate that the addition the earthworm casting in eutrophic soil promotes increase of dry mass of the aerial and total fast of the plant concentrations of earthworm casting $17.88 \%$ and $13.49 \%$, respectively. However, the results of experiment 2 indicate that the addition of the earthworm casting to the dystrophic soil, responds to a cubic function, with maximum dry mass total and of root increase with concentrations of earthworm casting of $17.49 \%$ and $21.40 \%$, respectively, with decrease in $68.23 \%$ and $67.48 \%$, and increase maximum again with $100 \%$ of earthworm casting for both characteristics. The use of substrate prepared with soil and earthworm casting only contributes to the growth of lettuce seedlings if the chemical condition of the casting is more appropriate than the one of the soil in assisting the nutritious needs of the plants.
\end{abstract}

Index terms: Lactuca sativa, organic fertilizer, Chibui bari.

\section{(Recebido em 13 de novembro de 2006 e aprovado em 19 de julho de 2007)}

\section{INTRODUÇÃO}

A alface (Lactuca sativa L.) é uma das hortaliças folhosas mais consumidas no Brasil, sendo amplamente cultivada em todos os Estados. Por ser uma espécie de região temperada, seu desempenho produtivo em campo é afetado pelas altas temperaturas e luminosidade. No Acre, predomina a opção pelas cultivares que não formam "cabeça" e tolerantes ao pendoamento precoce, pois nas

\footnotetext{
'Engenheira Agrônoma - Laboratório de Fitopatologia - Centro de Pesquisas Agroflorestais - Empresa Brasileira de Pesquisa Agropecuária/EMBRAPA Rodovia Br 364, Km 14 - Cx. P. 321 - 69908-970 - Rio Branco, AC - suzanasouza2004@yahoo.com.br

${ }^{2}$ Graduanda em Agronomia - Centro de Ciências Naturais e da Terra - Universidade Federal do Acre/UFAC - Campus Universitário, Br 364, Km 04 Cx. P. 500 - 69915-900 - Rio Branco, AC - yrlerocha@uol.com.br

${ }^{3}$ Engenheira Agrônoma - Centro de Ciências Naturais e da Terra - Universidade Federal do Acre/UFAC - Campus Universitário, Br 364 , Km 04 Cx.P. 500 - 69915-900 - Rio Branco, AC - szilagyi_agro@yahoo.com.br

${ }^{4}$ Engenheiro Agrônomo, Doutor em Fitotecnia, Professor Adjunto - Centro de Ciências Naturais e da Terra - Universidade Federal do Acre/UFAC Campus Universitário, Br 364, Km 04 - Cx. P. 500 - 69915-900 - Rio Branco, AC - selviro2000@yahoo.com.br

${ }^{5}$ Engenheiro Agrônomo, Doutor em Produção Vegetal, Professor Adjunto - Centro de Ciências Naturais e da Terra - Universidade Federal do Acre/UFAC Campus Universitário, Br 364, Km 04 - Cx. P. 500 - 69915-900 - Rio Branco, AC - kusdra@globo.com
} 
condições da região há dificuldade no fechamento da cabeça e antecipação do período reprodutivo, causando prejuízo na produtividade e qualidade do produto (LÉDO et al., 2000).

A produção de mudas constitui-se em uma das etapas mais importantes do cultivo da alface, pois dela depende o desempenho produtivo das plantas e a qualidade do produto destinado ao mercado consumidor. O substrato utilizado na produção de mudas exerce papel primordial, pois influencia o desenvolvimento inicial da planta. E é nesta fase que ocorre a definição do potencial produtivo da cultura. Segundo Minami et al. (1994), 60\% do sucesso de uma cultura depende do plantio de mudas de boa qualidade. Os substratos devem apresentar propriedades químicas e físico-hídricas de forma a melhorar a relação água/ar e caso melhore as condições físicas, o substrato pode apresentar maior disponibilidade de nutrientes (FERNANDES \& CORÁ, 2000), além disso, os substratos devem ser livres de sementes de plantas indesejáveis, nematódios ou outros patógenos, ter baixo custo e fácil aquisição (DINIZ et al., 2001; SOUZA \& RESENDE, 2003).

Por apresentar alta atividade microbiana e conter substâncias húmicas, os coprólitos de minhoca podem interferir favoravelmente na disponibilidade de nutrientes para as plantas, pois as substâncias húmicas são responsáveis pela retenção de nutrientes, impedindo sua lixiviação e aumentando a CTC do substrato (BENITES et al., 2005). Além da fertilidade do substrato, a principal característica do uso de coprólitos de minhoca na composição de substratos para produção de mudas é sua capacidade de retenção de umidade (BONILLA, 1992), pois altas concentrações de coprólitos proporciona maior densidade, e concentração de partículas sólidas, com diminuição direta da água disponível (GALVÃO et al., 2006).

Para a produção orgânica de mudas, deve se ter muito cuidado na qualidade do substrato, pois esta é mais exigida por não ser permitido recomendado a utilização de fertilizantes químicos de alta solubilidade (SOUZA \& RESENDE, 2003).

A viabilidade do uso de coprólitos da minhoca Chibui bari Righi \& Guerra, 1985 (Glossoscolecidae, Oligochaeta) como componente de substrato para produção de mudas, no Acre é justificável pela alta disponibilidade desse material na superfície de muitos solos. Guerra (1988), em estudos realizados no Parque Zoobotânico da Universidade Federal do Acre, verificou que esta espécie chega a produzir até 80 t.ha ${ }^{-1}$.ano ${ }^{-1}$ de excrementos.

Tendo em vista o potencial de uso dos coprólitos de minhoca como componente orgânico de substrato para produção de mudas objetivou-se com este trabalho avaliar seu efeito na produção de mudas de alface.

\section{MATERIAL E MÉTODOS}

Nos meses de maio a junho de 2005 foram realizados dois experimentos em casa de vegetação do Departamento de Ciências Agrárias da Universidade Federal de Acre. Em ambos foi utilizado o delineamento inteiramente casualizado, com seis tratamentos e seis repetições, totalizando 36 unidades experimentais, representadas por copos plásticos com capacidade de $180 \mathrm{~cm}^{3}$, perfurados no fundo e na lateral, de modo a promover boa drenagem.

Os tratamentos foram definidos a partir da mistura de coprólitos de minhoca (Chibui bari) e solo, sendo este eutrófico $(\mathrm{V}=79,63 \%)$ no Experimento 1 e distrófico ( $\mathrm{V}=28,68 \%)$ no Experimento 2 (Quadro 1).

Os coprólitos foram coletados da superfície do solo do Campus da Universidade Federal do Acre em área sob floresta secundária. Para a caracterização físico-química dos substratos realizaram-se as análises físicas (Quadro 2) e de fertilidade (Quadros 3 e 4) referentes a ambos os experimentos.

Quadro 1 - Composição dos substratos nos diferentes tratamentos nos dois experimentos.

\begin{tabular}{|ccccc|}
\hline \multirow{2}{*}{ Tratamento } & \multicolumn{2}{c|}{ Experimento 1 } & \multicolumn{2}{c|}{ Experimento 2 } \\
\cline { 2 - 5 } & Solo Eutrófico & Coprólito & Solo Distrófico & Coprólito \\
\hline T1 & $100 \%$ & $0 \%$ & $100 \%$ & $0 \%$ \\
T2 & $80 \%$ & $20 \%$ & $80 \%$ & $20 \%$ \\
T3 & $60 \%$ & $40 \%$ & $60 \%$ & $40 \%$ \\
T4 & $40 \%$ & $60 \%$ & $40 \%$ & $60 \%$ \\
T5 & $20 \%$ & $80 \%$ & $20 \%$ & $80 \%$ \\
T6 & $0 \%$ & $100 \%$ & $0 \%$ & $100 \%$ \\
\hline
\end{tabular}


Quadro 2-Características físicas dos substratos considerados como tratamentos dos experimentos 1 e 2.

\begin{tabular}{|c|c|c|c|c|c|c|c|c|c|c|c|c|}
\hline \multirow{3}{*}{ Tratamento } & \multicolumn{6}{|c|}{ Experimento 1 - Solo Eutrófico } & \multicolumn{6}{|c|}{ Experimento 2 - Solo Distrófico } \\
\hline & $\mathrm{Da}$ & $\mathrm{Dp}$ & $\mathrm{Pt}$ & Areia & Silte & Argila & $\mathrm{Da}$ & $\mathrm{Dp}$ & $\mathrm{Pt}$ & Areia & Silte & Argila \\
\hline & \multicolumn{2}{|c|}{$\mathrm{g} \mathrm{dm}^{-3}$} & \multicolumn{4}{|c|}{$(\%)$} & \multicolumn{2}{|c|}{$\mathrm{g} \mathrm{dm}^{-3}$} & \multicolumn{4}{|c|}{$(\%)$} \\
\hline T1 & 1,33 & 2,67 & 50 & 47 & 31 & 22 & 1,04 & 2,63 & 60 & 29 & 22 & 49 \\
\hline $\mathrm{T} 2$ & 1,24 & 2,50 & 50 & 51 & 31 & 18 & 1,09 & 2,60 & 58 & 33 & 26 & 41 \\
\hline $\mathrm{T} 3$ & 1,20 & 2,50 & 52 & 51 & 32 & 17 & 1,11 & 2,60 & 57 & 35 & 32 & 33 \\
\hline $\mathrm{T} 4$ & 1,16 & 2,47 & 53 & 48 & 36 & 16 & 1,10 & 2,50 & 56 & 42 & 33 & 25 \\
\hline T5 & 1,13 & 2,44 & 54 & 47 & 41 & 12 & 1,13 & 2,44 & 54 & 43 & 39 & 18 \\
\hline T6 & 1,17 & 2,38 & 51 & 49 & 41 & 10 & 1,17 & 2,38 & 51 & 49 & 41 & 10 \\
\hline
\end{tabular}

Da - Densidade aparente a base seca; Dp - Densidade das partículas; Pt - Porosidade total.

Quadro 3 - Composição química dos substratos com diferentes concentrações de coprólitos de minhoca em solo eutrófico (SE). Experimento 1.

\begin{tabular}{|c|c|c|c|c|c|c|c|c|c|c|c|c|}
\hline \multirow[t]{2}{*}{ Tratamento } & $\mathrm{pH}$ & $\mathrm{Na}$ & K & $\mathrm{Ca}$ & $\mathrm{Mg}$ & $\mathrm{Al}$ & $\mathrm{H}+\mathrm{Al}$ & SB & $\mathrm{T}$ & \multirow{2}{*}{$\begin{array}{l}\mathrm{V} \\
(\%)\end{array}$} & \multirow{2}{*}{$\begin{array}{c}\text { M.O. } \\
\text { dag kg }^{-1}\end{array}$} & \multirow{2}{*}{$\begin{array}{l}\text { P-rem } \\
\mathrm{mg} \mathrm{l}^{-1}\end{array}$} \\
\hline & $\left(\mathrm{H}_{2} \mathrm{O}\right)$ & \multicolumn{8}{|c|}{$\mathrm{cmol}_{\mathrm{c}} \mathrm{dm}^{-3}$} & & & \\
\hline $\mathrm{T} 1$ & 5,0 & 0,04 & 0,21 & 5,50 & 1,60 & 0,25 & 1,88 & 7,35 & 9,23 & 79,63 & 9,99 & 17 \\
\hline $\mathrm{T} 2$ & 4,7 & 0,08 & 0,19 & 4,95 & 1,45 & 0,15 & 2,82 & 6,67 & 9,49 & 70,28 & 12,95 & 20 \\
\hline T3 & 4,7 & 0,08 & 0,18 & 4,25 & 1,75 & 0,25 & 3,43 & 6,26 & 9,69 & 64,60 & 15,44 & 20 \\
\hline $\mathrm{T} 4$ & 4,6 & 0,08 & 0,18 & 3,50 & 2,00 & 0,35 & 4,13 & 5,76 & 9,89 & 58,24 & 16,83 & 19 \\
\hline T5 & 4,5 & 0,04 & 0,17 & 3,25 & 1,60 & 0,35 & 3,99 & 5,06 & 9,05 & 55,91 & 23,74 & 17 \\
\hline T6 & 4,4 & 0,04 & 0,13 & 2,45 & 1,65 & 0,60 & 4,70 & 4,27 & 8,97 & 47,60 & 19,29 & 18 \\
\hline
\end{tabular}

Quadro 4 - Composição química dos substratos com diferentes concentrações de coprólitos de minhoca em solo distrófico (SD). Experimento 2.

\begin{tabular}{|c|c|c|c|c|c|c|c|c|c|c|c|c|}
\hline \multirow[t]{2}{*}{ Tratamento } & $\mathrm{pH}$ & $\mathrm{Na}$ & $\mathrm{K}$ & $\mathrm{Ca}$ & $\mathrm{Mg}$ & $\mathrm{Al}$ & $\mathrm{H}+\mathrm{Al}$ & SB & $\mathrm{T}$ & \multirow{2}{*}{$\begin{array}{l}\mathrm{V} \\
(\%)\end{array}$} & \multirow{2}{*}{$\begin{array}{c}\text { M.O. } \\
\text { dag.kg-1 }\end{array}$} & \multirow{2}{*}{$\begin{array}{c}\mathrm{P}- \\
\text { rem } \\
\mathrm{mg} \mathrm{l}^{-1}\end{array}$} \\
\hline & $\left(\mathrm{H}_{2} \mathrm{O}\right)$ & \multicolumn{8}{|c|}{$\mathrm{cmol}_{\mathrm{c}} \mathrm{dm}^{-3}$} & & & \\
\hline $\mathrm{T} 1$ & 4,0 & 0,04 & 0,13 & 0,30 & 0,70 & 1,75 & 2,91 & 1,17 & 4,08 & 28,68 & 1,66 & $<1$ \\
\hline $\mathrm{T} 2$ & 4,0 & 0,04 & 0,13 & 1,00 & 1,00 & 1,65 & 3,99 & 2,17 & 6,16 & 35,23 & 6,01 & 2 \\
\hline $\mathrm{T} 3$ & 4,0 & 0,04 & 0,13 & 1,40 & 1,00 & 1,40 & 4,51 & 2,57 & 7,08 & 36,30 & 11,56 & 5 \\
\hline $\mathrm{T} 4$ & 4,1 & 0,04 & 0,11 & 1,50 & 1,40 & 1,15 & 5,26 & 3,05 & 8,31 & 36,70 & 14,89 & 9 \\
\hline $\mathrm{T} 5$ & 4,2 & 0,04 & 0,11 & 1,60 & 1,40 & 1,00 & 4,32 & 3,15 & 7,47 & 42,17 & 16,83 & 15 \\
\hline T6 & 4,4 & 0,04 & 0,13 & 2,45 & 1,65 & 0,60 & 4,70 & 4,27 & 8,97 & 47,60 & 19,29 & 18 \\
\hline
\end{tabular}

Antes de efetuar-se a mistura dos coprólitos aos respectivos solos, de acordo com as proporções definidas nos tratamentos, estes foram passados em peneira com abertura de malha igual a $0,5 \mathrm{~cm}$, misturados e homogeneizados em sacos plásticos e, posteriormente, acondicionados nos recipientes.

Como planta teste foi usada a alface cultivar Simpson, que se caracteriza por apresentar folhas crespas com coloração verde-clara, consistentes e soltas, não formando cabeça. A semeadura foi realizada em bandeja contendo areia lavada e, seis dias após, as plântulas consideradas mais uniformes, foram repicadas para os copos plásticos, sendo uma para cada unidade experimental. A irrigação foi realizada diariamente visando manter o substrato com umidade próxima à capacidade de armazenamento d'água ("capacidade de campo"), que não foi determinada, porém atingida logo após a irrigação através da drenagem do excesso de água pelos furos nos recipientes. 
As avaliações foram feitas aos 28 dias após a repicagem, considerando as seguintes variáveis indicadoras de crescimento: massa seca da parte aérea; massa seca da raiz e massa seca total. Primeiramente efetuou-se o corte da parte aérea das plantas que foi acondicionado em sacos de papel, onde permaneceu até secagem completa. As raízes foram lavadas usando-se peneira de malha fina para evitar a perda de material. Posteriormente, tanto a parte aérea como as raízes foram colocadas para secar em estufa regulada a $60{ }^{\circ} \mathrm{C}$ até obtenção de massa constante. A massa seca total da planta foi obtida somando-se as massas de massa seca da raiz e da parte aérea. Os resultados de todas as características avaliadas em ambos os experimentos foram submetidos à análise de regressão.

\section{RESULTADOS E DISCUSSÃO}

No experimento utilizando-se substratos obtidos pela mistura de coprólitos e solo eutrófico verificou-se diferença significativa entre os tratamentos para as massas seca da parte aérea, da raiz e total da planta (Figura 1).

As massas da massa fresca e seca da parte aérea e total da planta aumentaram quando a concentração de coprólito na composição do substrato atingiu um máximo de $17,88 \%$ e $13,49 \%$, respectivamente, decrescendo a partir de concentrações superiores a esses valores.

Os coprólitos apresentaram, de modo geral, fertilidade menos favoráveis em fornecer nutrientes para as plantas (Quadro 3). Portanto, a condição de fertilidade do substrato foi sendo gradativamente reduzida na medida que o solo foi sendo substituído por níveis crescentes de coprólito. Considerando essa situação justifica-se, do ponto de vista químico, qualquer diminuição no crescimento das plantas associada as maiores concentrações de coprólito na composição do substrato. Entretanto, a qualidade do substrato não depende apenas de sua condição química havendo outros fatores, especialmente físicos, que definem seus efeitos no crescimento das plantas.

Assim, com a adição de coprólito, a qualidade física foi melhorada, pois proporcionou menor densidade e maior porosidade (Quadro 2) o que melhora a drenagem, aeração e respiração proporcionando bom desenvolvimento radicular aumentando a área de absorção de nutrientes pelas plantas (KONRAD et al., 2001). No entanto, a diminuição da qualidade química foi mais determinante no

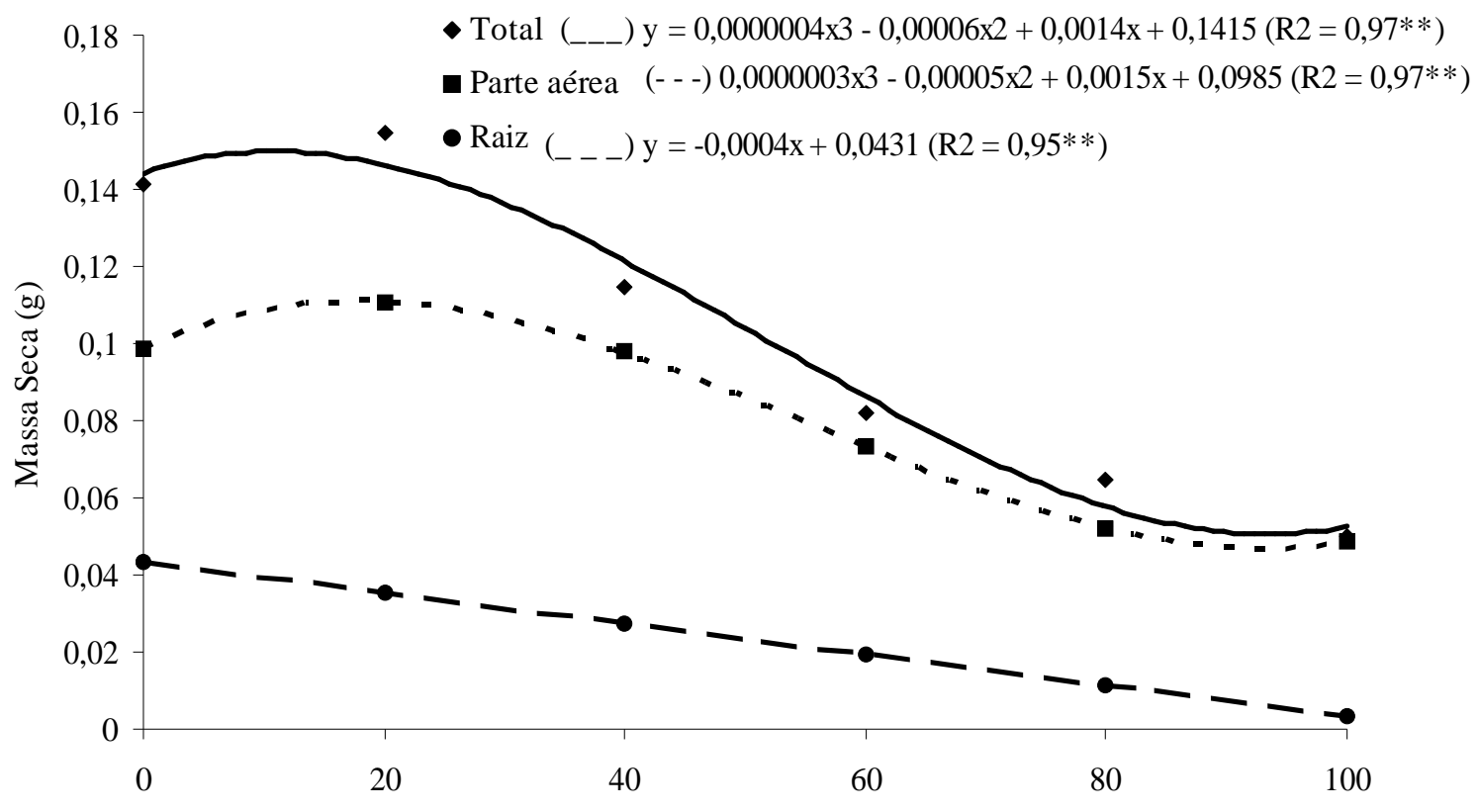

Concentração de Coprólitos na Composição Volumétrica do Substrato (\%)

Figura 1 - Massa seca da parte aérea, da raiz e total da alface em função de substrato preparado a base de coprólito de minhocas e solo eutrófico. 
incremento de massa, pois observa-se um decréscimo nos teores de Ca e K (Quadro 3). Esses elementos constituem o $1^{\circ}$ e $3^{\circ}$ nutrientes mais absorvido pela alface (KATAYAMA, 1993), além disso, o K encontrava-se com teor abaixo do ótimo recomendado para substrato, que

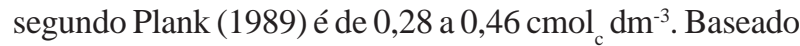
na recomendação do mesmo autor, os demais elementos estão acima dos teores ótimos para substratos: 0,7 a 1,2 $\mathrm{cmol}_{c}$ $\mathrm{dm}^{-3}$ para Ca; 8 a $13 \mathrm{mg} \mathrm{L}^{-1}$ de P; 0,5 a 0,83 $\mathrm{cmol}_{\mathrm{c}} \mathrm{dm}^{-3} \mathrm{de} \mathrm{Mg}^{\mathrm{c}}$ no experimento com solo eutrófico (Quadro 3).

Além da diminuição de Ca e K, verificou-se aumento de $\mathrm{Al}^{3+}+\mathrm{H}^{+}$e $\mathrm{Al}^{3+}$ trocável, significando que a acidez ativa do substrato aumentou ocasionando decréscimo no valor de $\mathrm{pH}$ (de 5,0 para 4,4). O valor de pH é muito importante, e baixos valores podem incrementar a disponibilidade de alguns macronutrientes (Ca, Mg e P) e causar fitotoxicidade por outros (Fe, Mn, Zn, Cu) (BAILEY et al., 2007). Dessa forma, entre valores de $\mathrm{pH}$ de 6,0 a 7,0 ocorre adequada disponibilidade de nutrientes nos substratos minerais, mas para substratos orgânicos, esse valor varia de 5,2 a 5,5 (KÄMPF, 2000), portanto, o pH dos substratos avaliados encontravam-se bem abaixo do recomendado.

Analisando os resultados da massa seca da raiz verifica-se que na medida que aumentaram-se as concentrações de coprólito na composição do substrato, houve redução de seu crescimento (Figura 1).
Entre os fatores que podem ter contribuído para a ocorrência da diminuição do crescimento radicular pode estar a redução gradativa do nível de cálcio no substrato, na medida que o solo foi sendo substituído por concentrações crescentes de coprólito. O cálcio é um elemento fundamental para a alface de um modo geral (KATAYAMA, 1993) e em especial ao crescimento das raízes das plantas (POTAFOS, 1996) e verificou-se forte correlação $\left(r=0,9863^{* *}\right)$ entre seu teor no substrato e a massa seca das raízes.

Além de diminuir a fertilidade dos substratos, a adição de coprólitos acima de 21,40\%, aumentou a porcentagem de partículas de tamanho grande (areia e silte) e diminui as de tamanho pequeno (argila). Segundo Fernandes et al. (2006) esta condição proporciona menos espaço de aeração e maior drenagem, diminuindo a água facilmente disponível.

No experimento utilizando-se substratos obtidos pela mistura de coprólitos e solo distrófico verificou-se diferença significativa entre os tratamentos para as massas secas da raiz e total da planta (Figura 2). Essas características apresentaram um pequeno acréscimo quando a concentração de coprólito na composição do substrato passou de $0 \%$ para $17,49 \%$ e $21,40 \%$, respectivamente, decrescendo até concentrações de $68,23 \%$ e $67,48 \%$, respectivamente, tendo grande aumento em concentrações acima desse valor.

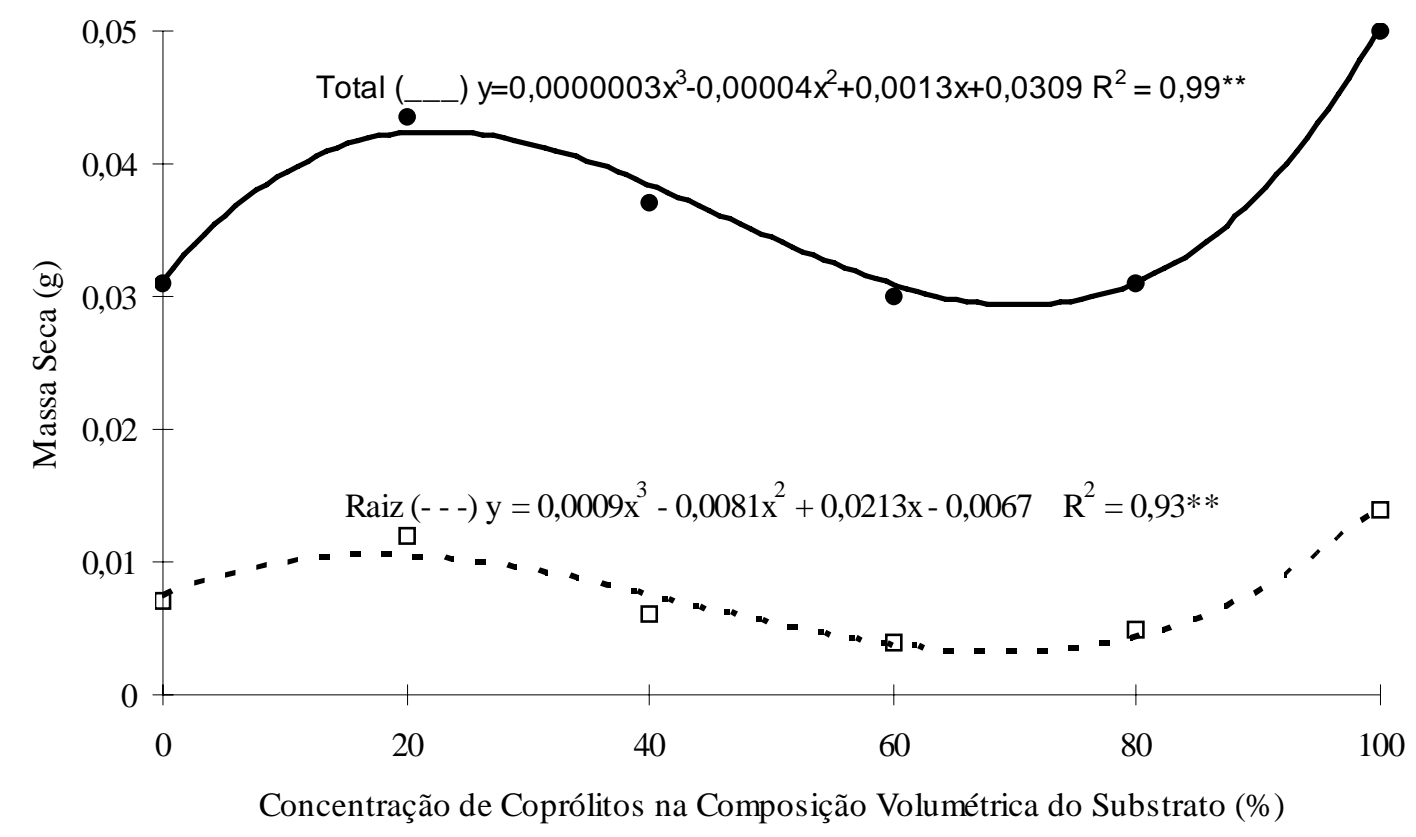

Figura 2 - Massa seca da raiz e total da alface em função de substrato preparado a base de coprólito de minhocas e solo distrófico. 
Neste experimento, ao contrário do que ocorreu no experimento 1, as características químicas do solo ofereciam, de modo geral, condições menos favoráveis que as dos coprólitos em fornecer nutrientes para as plantas (Quadro 4). Portanto, o nível de fertilidade dos substratos foi sendo gradativamente melhorado na medida que o solo foi sendo substituído por níveis crescentes de coprólito. Do ponto de vista químico esperava-se, conseqüentemente, que maiores concentrações de coprólito na composição do substrato resultassem em aumento na massa seca das plantas. Entretanto essa situação se verificou apenas nas concentrações de coprólito até 17,49\% e 21,40\%, para massa seca de raiz e total, respectivamente, e para concentrações maiores que $67,48 \%$. Dessa forma outras características, especialmente as físicas, interferem de forma decisiva no desempenho das plantas em relação à composição do substrato.

Neste solo, a incorporação de coprólitos promoveu aumento das concentrações de $\mathrm{Ca}, \mathrm{Mg}, \mathrm{P}$ e M.O., além de elevar o pH e diminuir a concentração de $\mathrm{Al}^{+3}$ (Quadro 4), fatores estes que, segundo Malavolta et al. (1997), favorecem o crescimento das plantas. A diminuição dos teores de massa seca da total da planta, nas concentrações entre $21,40 \%$ a $67,48 \%$ de coprólitos pode ter ocorrido pelo aumento da densidade, diminuição da porosidade, aumento da porcentagem de partículas maiores (areia e silte), condição esta que Fernandes et al. (2006) afirmam diminuir o espaço de aeração, aumentar a drenagem e reduzir a água facilmente disponível, fatores estes que comprometem a qualidade físico-hídrica dos substratos e o desenvolvimento das plantas (FERNANDES \& CORÁ, 2000). Esta situação ocasiona maior retenção de água, diminuindo a quantidade de poros ocupados por ar, dificultando a respiração e limitando o desenvolvimento radicular que reduz a área de absorção de nutrientes.

Analisando a fertilidade do substrato, observa-se que este foi o fator determinante do baixo desempenho das plantas. $\mathrm{O}$ valor de $\mathrm{pH}$ neste experimento $(4,0$ a 4,4) manteve-se muito abaixo do recomendado para substratos orgânicos, que segundo Kämpf (2000) deve estar entre 5,2 a 5,5. Aliado ao aumento nos teores de $\mathrm{Al}^{3+}+\mathrm{H}^{+}$há influencia negativa na solubilidade de nutrientes como $\mathrm{Ca}$, $\mathrm{Mg}, \mathrm{P}$ e $\mathrm{K}$ deixando-os indisponíveis para as plantas ou intoxicando-as com Fe, Mn, Zn e Cu (BAILEY et al., 2007; TISDALE et al., 1999), pois o crescimento das mudas neste experimento foi menor que no anterior, mesmo respondendo na concentração de $100 \%$ de coprólito. Nesta concentração, houve aumento significativo do teor de $\mathrm{P}$, M.O., $\mathrm{Mg}$ e Ca, superando a condição física desfavorável.
O uso de substratos preparados com solo e coprólitos de minhoca somente contribui para o crescimento de mudas de alface se a condição química dos coprólitos for mais adequada que a do solo em atender às necessidades nutricionais das plantas. E sua mistura não deve ultrapassar 13,40\% em solos eutróficos ou 21,40 em solos distróficos.

\section{REFERÊNCIAS BIBLIOGRÁFICAS}

BAILEY, D. A. et al. Substrates pH and water quality. Raleigh: North Carolina Sate University, 2000. Disponível em: <http://www.ces.ncsu.edu/depts/hort/floriculture/ plugs/ph.pdf>. Acesso em: 15 jan. 2007.

BENITES, V. M.; MADARI, B.; BERNARDI, A. C. C.; MACHADO, P. L. O. Matéria orgânica do solo. In: WADT, P. G. S. (Ed.). Manejo de solo e recomendação de adubação para o Estado do Acre. Rio Branco: Embrapa Acre, 2005. p. 93-120.

BONILLA, J. A. Fundamentos da agricultura ecológica: sobrevivência e qualidade de vida. São Paulo: Nobel, 1992. $260 \mathrm{p}$.

DINIZ, K. A.; LUZ, J. M. Q.; MARTINS, S. T.; DUARTE, L. C. Produção de mudas de tomate e pimentão em substrato a base de vermicomposto. Horticultura Brasileira, Brasília, v. 19, 2001. Suplemento. CD-ROM.

FERNANDES, C.; CORÁ, J. E. Caracterização físico-hídrica de substratos utilizados na produção de mudas de espécies olerícolas e florestais. Horticultura Brasileira, Brasília, v. 18, p. 469-471, 2000. Suplemento.

FERNANDES, C.; CORÁ, J. E.; BRAZ, L. Desempenho de substratos no cultivo do tomateiro do grupo cereja. Horticultura Brasileira, Brasília, v. 24, n. 1, p. 42-46, jan./ mar. 2006.

GALVÃO, R. O.; ARAÚJO NETO, S. E. de; SANTOS, F. C. B. dos; SILVA, S. S. da. Desempenho de mudas de mamoeiro cv. Sunrise Solo sob diferentes substratos orgânicos. In: SEMINÁRIO DE INICIAÇÃO CIENTÍFICA, 16., 2006, Rio Branco. Anais... Rio Branco: UFAC/Embrapa/CNPq, 2006. CD-ROM.

GUERRA, R. T. Ecologia dos Oligochaeta da Amazônia: II. estudo da estivação e da atividade de Chibui bari (Glossoscolecidae, Oligochaeta) através da produção de excrementos. Acta Amazônica, Manaus, v. 18, n. 1, p. 27 34, 1988. 
KÄMPF, A. N. Seleção de materiais para uso como substrato. In: KÄMPF, A. N.; FERMINO, M. H. (Eds.). Substrato para plantas: a base da produção vegetal em recipientes. Porto Alegre: Gênesis, 2000. p. 139145 .

KATAYAMA, M. Nutrição e adubação de alface, chicória e almeirão. In: FERREIRA, M. E.; CASTELLANE, P. D.; CRUZ, M. C. P. da. (Eds.). Nutrição e adubação de hortaliças. Piracicaba: Potafos, 1993. p. 141-148.

KONRAD, M.; HERNANDEZ, F. B. T.; SANTOS, R. A. Distribuição espacial do sistema radicular da aceroleira em um solo podzólico vermelho amarelo. In: CONGRESSO BRASILEIRO DE ENGENHARIA AGRÍCOLA, 30., 2001, Foz do Iguaçu. Anais... Foz do Iguaçu: Sociedade Brasileira de Engenharia Agrícola; Universidade Estadual do Oeste do Paraná, 2001.

LÉDO, F. J. S.; SOUSA, J. A.; SILVA, M. R. Desempenho de cultivares de alface no Estado do Acre. Horticultura Brasileira, Brasília, v. 18, n. 2, p. 225-228, 2000.
MALAVOLTA, E.; VITTI, G. C.; OLIVEIRA, S. A. de. Avaliação do estado nutricional das plantas: princípios e aplicações. 2. ed. Piracicaba: Potafos, 1997. 319 p.

MINAMI, K.; TESSARIOLI NETO, J.; PENTEADO, S. R.; ESCARPARI FILHO, J. A. Produção de mudas hortícolas de alta qualidade. Piracicaba: ESALQ/SEBRAE, 1994. 155 p.

PLANK, C. O. Soil test handbook for Georgia. Athens: University of Georgia, 1989. 316 p.

POTAFOS. Nutrifatos: informação agronômica sobre nutrientes para as culturas. Arquivo do Agrônomo, [S.1.], n. 10, 1996.

SOUZA, J. L.; RESENDE, P. Manual de horticultura orgânica. Viçosa: Aprenda Fácil, 2003. 546 p.

TISDALE, S. L.; HAVLIN, J. L.; BEATON, J. D.; NELSON, W. L. Soil fertility and fertilizers: an introduction to nutrient management. 6. ed. New Jersey: Prentice Hall, 1999. $499 \mathrm{p}$. 